\title{
61. The Role of Symbiotic Chlorella in Photoresponses of Paramecium bursaria
}

\author{
By Kenji IwatsukI and Yutaka NaITOH \\ Institute of Biological Sciences, University of Tsukuba, Ibaraki 305 \\ (Communicated by Setsuro EBASHI, M. J. A., Oct. 12, 1981)
}

Paramecium bursaria is a ciliate protozoan which is inhabited by symbiotic green algae, Chlorella. ${ }^{1), 2)}$ When a forward swimming specimen of $P$. bursaria encounters a shaded area, it exhibits avoiding response (klinophobic response ${ }^{3)}$ ) due to a transient reversal of the beating direction of cilia. ${ }^{4), 5)}$ The specimen accordingly tends to stay in a lighted area (photoaccumulation ${ }^{3)}$ ). The avoiding response is caused by a relative decrease in the light intensity (step-down stimulation), thus obeys Weber-Fechner's law. ${ }^{6)}$

It has been generally accepted that photosensitivity of $P$. bursaria is mediated by the presence of symbiotic Chlorella. The cloning of Chlorella-free P. bursaria*) provides an opportunity of studying the mechanism by which the symbiotic algae mediate the photosensitivity of their host. We examined the response to light in specimens of $P$. bursaria both with and without the symbiotic algae.

We found that Chlorella-free specimens showed avoiding response to a photostimulation. The response, however, was mostly caused by a relative increase in the light intensity (step-up stimulation) in contrast to the normal, Chlorella-containing specimens. The specimens, accordingly, tended to gather in a shaded area (photodispersal $^{3)}$ ). When the Chlorella-free specimens ingested Chlorella, they began to show avoiding response to a step-down stimulation (stepdown response) and photoaccumulation as do the Chlorella-containing specimens. On the other hand, the Chlorella-containing specimens began to show avoiding response to a step-up stimulation (step-up response) and photodispersal as do the Chlorella-free specimens, when they were kept in the dark. The action spectrum for the photodispersal was identical with that in the Chlorella-free specimens. When dark-adapted specimens were exposed to light, they recovered their ability to show the step-down response and photoaccumulation. Presence of 3-(3,4-dichlorophenyl)-1,1-dimethylurea (DCMU), which

*) Chlorella-free specimens used in the present experiments were obtained by Tsukii, Y., and Hiwatashi, K. of Tohoku Univ. by keeping the normal Chlorellacontaining specimens starved and unilluminated. No genetic modifications were found in the specimens. 
is an inhibitor of photosynthesis, ${ }^{7)}$ in the external solution $(1 \times$ $\left.10^{-5} \mathrm{M} / \mathrm{l}\right)$ never retarded the light-induced recovery of the step-down response and photoaccumulation. A blue light (about $480 \mathrm{~nm}$ in its wavelength) was most effective for the recovery. We concluded that $P$. bursaria intrinsically possesses photoresponsivity and that its symbiotic Chlorella alter the intrinsic step-up response to step-down response, thereby facilitating the specimen to stay in a lighted region, where photosynthesis of Chlorella is activated.

$P$. bursaria were cultured in a wheat-straw infusion at $21^{\circ} \mathrm{C}$. All the cultures were maintained on a fixed illumination cycle of $12 \mathrm{hrs}$ dark and $12 \mathrm{hrs}$ light (2000 lux fluorescent lamp) in order to keep the diurnal rhythm of phototactic and thigmotactic responses constant. ${ }^{8), 9)}$ Light-adapted specimens were obtained from the cultures $3 \mathrm{hrs}$ after the light was on. Dark-adapted specimens were obtained from the cultures $8 \mathrm{hrs}$ after the light was off. All the specimens were washed with a standard saline solution $(1 \mathrm{mM} \mathrm{KCl}, 1 \mathrm{mM}$ $\mathrm{CaCl}_{2}$ and $1 \mathrm{mM}$ Tris-HCl; $\left.\mathrm{pH} 7.2\right) .{ }^{10)}$

Chlorella-free specimens ingested Chlorella when they were mixed with the algae, ${ }^{11)}$ which had been isolated from the Chlorellacontaining $P$. bursaria by being crushed by filtering through a filter with a pore size of $8 \mu \mathrm{m}$ (Nuclepore Corp. Pleasanton, California). The number of Chlorella incorporated within the cell was controlled by varying the duration of contact.

Prior to photostimulation the specimens in an experimental vessel (diameter, $30 \mathrm{~mm}$; depth, $5 \mathrm{~mm}$ ) were kept in a conditioning light (1500 lux) for 2 mins. The light intensity was suddenly increased to 4000 lux (step-up stimulation), being kept constant at this level for 2 mins. Then it was suddenly decreased to the original conditioning level (step-down stimulation). The light intensity was controlled by putting a neutral density filter in front of an incandescent lamp.

The avoiding response exhibited by the specimens upon a photostimulation was monitored on a picture tube and recorded on videotape. The number of specimens which showed the response was counted on the playbacked picture.

In order to demonstrate photoaccumulation and photodispersal, the specimens were introduced into a glass tube $(4 \mathrm{~cm}$ in length, $4 \mathrm{~mm}$ in inner diameter), half the length of which was covered by blackened foil. The tubes were placed horizontally under illumination for a certain period of time. The foil was then removed and the tubes were photographed under darkfield illumination for recording the distribution of the specimens.

Monochromatic light (half-band width; less than $18 \mathrm{~nm}$ ) was 
obtained by combined use of interference and color filters.

As shown in Fig. 1A, more than $60 \%$ of Chlorella-free specimens exhibited avoiding response upon a step-up stimulation. Only 10\% of the specimens showed an avoiding response to a step-down stimulation. In accordance with increasing number of Chlorella incorporated in the specimens the number of specimens which showed the step-down response increased and exceeded that of specimens which showed the step-up response, when the number of Chlorella was more than 100. Normal specimens, which contain about 500 Chlorella, showed only the step-down response.
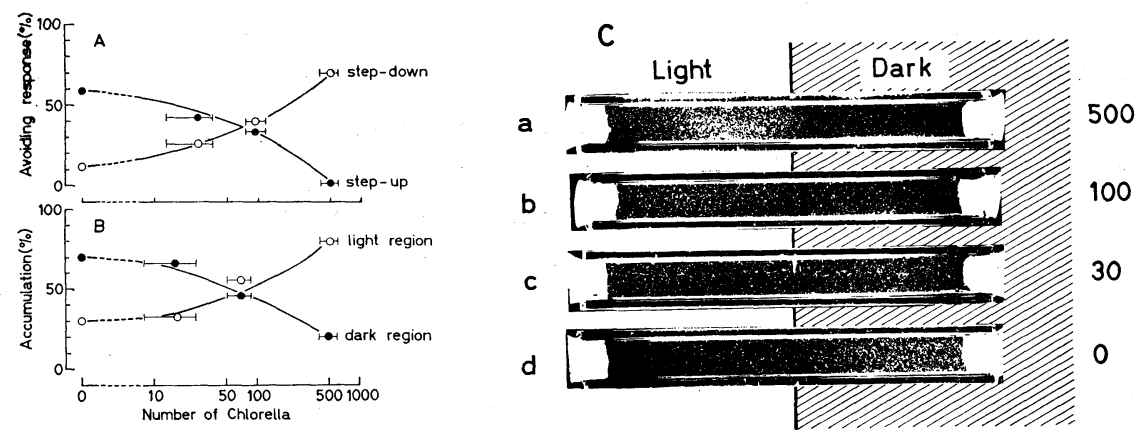

Fig. 1. Effects of symbiotic Chlorella on the photoresponses in Paramecium bursaria. A : Number of specimens which showed step-down response (open circles) and step-up response (solid circles) in percent of the total number of specimens examined at random. B: Number of specimens which showed photoaccumulation (open circles) and photodispersal (solid circles) in the half-shaded glass tube in percent of total number of specimens in the tube. C: Distribution of the specimens in the glass tube. Numerals on the right side represent the number of Chlorella incorporated in the cell. Data presented in $\mathbf{B}$ are based on the photographs in $\mathrm{C}$.

The distribution of Chlorella-free specimens in the half-shaded glass tube in 10 mins illumination also altered when they ingested Chlorella. As shown in Fig. 1C, most of the Chlorella-free specimens gathered in the shaded region of the tube. With increasing number of Chlorella the specimens began to gather in the lighted region. Most of the normal specimens gathered in the lighted region. The percentage of the specimens that accumulated in the lighted region (and in the shaded region) is shown in Fig. 1B as a function of the mean number of Chlorella in the cells. The striking similarity between the effect of Chlorella on the step-down (step-up) response and that on the photoaccumulation (photodispersal) strongly suggests that the photoaccumulation (photodispersal) of the specimens was depen- 
dent primarily on the avoiding response exhibited by the specimens at the border between light and dark regions, at least under present experimental condition.*)

The percentage of the specimens which showed photoaccumulation was plotted against wavelength of monochromatic light to which the specimens in the tube were exposed for 2 mins (Fig. 2). Photoaccumulation of less than $50 \%$ means that the specimens gathered more in the shaded region than in the lighted region (photodispersal). The action spectrum for the photoaccumulation in the Chlorella-containing specimens showed a rather broad peak at around $520 \mathrm{~nm}$ being different from that for photosynthesis in Chlorella $(440 \mathrm{~nm}$ and $680 \mathrm{~nm}){ }^{12}$ ) while that for the photodispersal in the Chlorella-free specimens showed two peaks at $540 \mathrm{~nm}$ and $680 \mathrm{~nm}$ respectively. Some researchers ${ }^{13), 14)}$ reported action spectra different from ours. The differences might be attributable to differences in the method for determining the action spectrum and also in the experimental conditions.

It is noteworthy that the Chlorella-containing specimens became to show step-up response and photodispersal as do the Chlorella-free specimens, when they were in the dark period of illumination cycle. The action spectrum for the photodispersal was identical with that

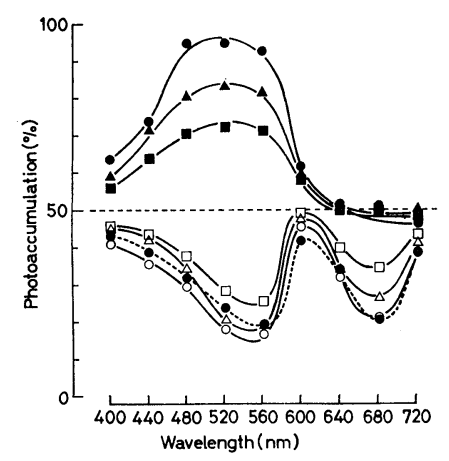

Fig. 2. Action spectra for the photoaccumulation in Paramecium bursaria. The accumulation was examined in three different light intensities (circles, 4 ; triangles, 2 ; squares, 1 all in $10^{18}$ quanta $\mathrm{m}^{-2} \mathrm{sec}^{-1}$ ). Solid symbols, Chlorella-containing specimens. Open symbols, Chlorella-free specimens. A dotted line with solid circles, dark-adapted Chlorella-containing specimens.

*) Factors affecting the distribution other than the avoiding response seen at the border are frequency of spontaneous avoiding response and swimming velocity. Thigmotactic behavior (specimens stop swimming, attach on the bottom of the vessel and sometimes crawl) also alters the distribution, since the photoresponse is different between the swimming specimens and attached specimens. Shape of the vessels is also an important factor for the distribution. 
in the Chlorella-free specimens (Dotted line in Fig. 2). The darkadapted specimens gradually changed so as to show step-down response and photoaccumulation when they were kept illuminated. The light-induced change in the photoresponse was not inhibited by DCMU $^{7}$ in the external solution, while it was proved to inhibit production of oxygen by the symbiotic Chlorella in the light.

As shown in Fig. 3, a monochromatic light with wavelength of about $480 \mathrm{~nm}$ (blue light) was most effective in altering the step-up response to step-down response. Therefore, it is conceivable that the blue light effect in the symbiotic Chlorella ${ }^{15)}$ might be involved in the mechanism which controls the photoresponses in $P$. bursaria.

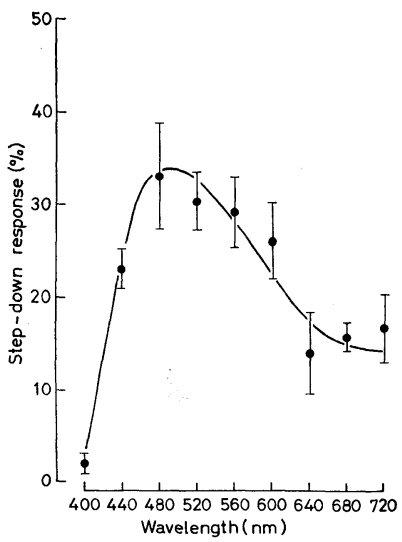

Fig. 3. Action spectrum for the light-induced alteration of the photoresponse in dark-adapted Chlorella-containing Paramecium bursaria from step-up to step-down response. The specimens were exposed to monochromatic light $\left(4 \times 10^{18}\right.$ quanta $\mathrm{m}^{-2} \mathrm{sec}^{-1}$ ) for two hours before examining their photoresponse. Increased number of specimens which showed stepdown response in percent of the total number of specimens $(30-40)$ was plotted against wavelength. Vertical lines, standard error of each mean of three different series of experiments.

We thank Dr. T. Ikawa for valuable suggestions and Dr. R. LeBrasseur for critical reading of the manuscript. The work was supported by grants from Mitsubishi Foundation and from Ministry of Education of Japan to Y.N. (144006, 411802, 411808, 510902, 511201). Parts of the present works were orally presented at the annual meeting of the Zoological Society of Japan in $1978,{ }^{8)} 1979^{9)}$ and $1980 .{ }^{16)}$

Addendum. Niess, Reisser and Weissner recently (1981) reported photoaccumulation of $P$. bursaria dependent of photosynthetic activity in the symbiotic Chlorella (Planta, vol. 152, p. 268). This 
shows more variety in the photobehavior in this specimen (see the footnote on p. 321).

\section{References}

1) Muscatine, L., Karakashian, S. J., and Karakashian, M. W.: Comp. Biochem. Physiol., 20, 1 (1967).

2) Brown, J. A., and Nielsen, P. J.: J. Protozool., 21, 569 (1974).

3) Diehn, B.: Handbook of Sensory Physiology (ed. Autrum, H.). SpringerVerlag, Berlin, Heidelberg, New York, p. 23 (1979).

4) Engelmann, T. W.: Arch. Ges. Physiol., 29, 387 (1882).

5) Jennings, H. S.: Behavior of The Lower Organisms. Columbia University Press, New York, p. 72 (1906).

6) Saji, M., and Oosawa, F.: J. Protozool., 26, 556 (1974).

7) Bishop, N. I.: Biochem. Biophys. Acta, 27, 205 (1958).

8) Iwatsuki, K., and Naitoh, Y.: Dobutsugaku Zassi (Zool. Mag. Tokyo), 87, 427 (1978).

9) - : ibid., 88, 528 (1979).

10) Naitoh, Y., and Eckert, R.: Experiments in Physiology and Biochemistry (ed. Kertut, G. A.). Academic Press, London, New York, p. 17 (1972).

11) Bomford, R.: J. Protozool., 12, 221 (1965).

12) Haxo, F. T.: Comparative Biochemistry of Photoreactive Pigments (ed. Allen, N. B.). Academic Press, New York, p. 339 (1960) .

13) Pado, R.: Acta Protozool., 11, 387 (1972).

14) Henry, A. S., and Nielsen, P. J.: J. Protozool., 27, 32A (1980).

15) Kamiya, A., and Miyachi, S.: Plant \& Cell Physiol., 15, 927 (1974).

16) Iwatsuki, K., and Naitoh, Y.: Dobutsugaku Zasshi (Zool. Mag. Tokyo), 89, $436(1980)$. 